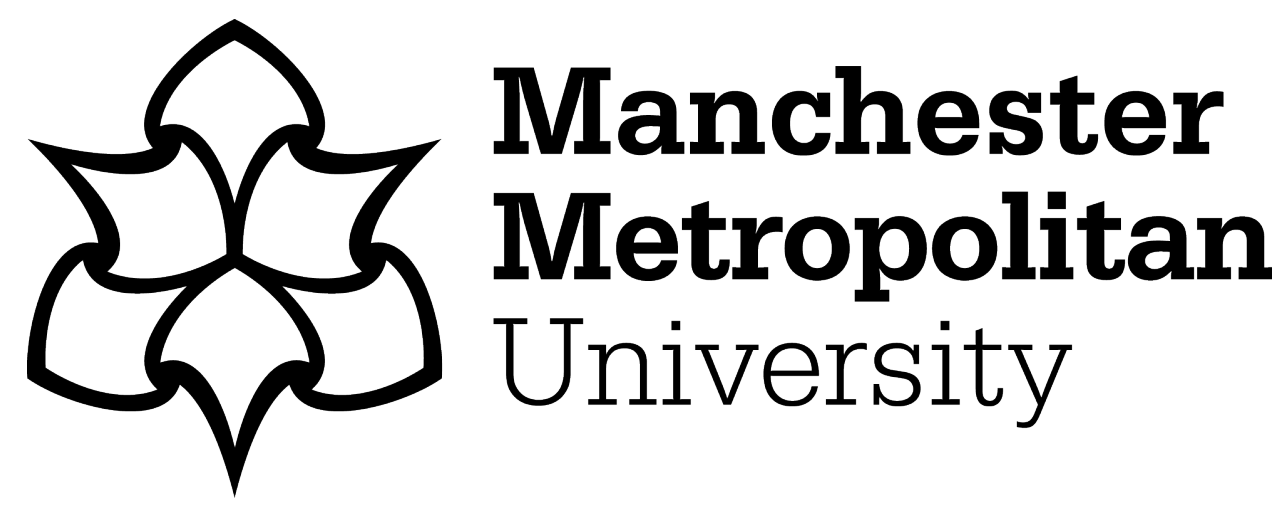

Faulkner, Simon (2018) Photographic witnessing, the occupation and Palestinian politics. In: Image Testimonies: Witnessing in Times of Social Media. Routledge Studies in Affective Societies . Routledge. ISBN 1138343064

Downloaded from: https://e-space.mmu.ac.uk/622220/

Version: Accepted Version

Publisher: Routledge

Please cite the published version 


\title{
Photographic witnessing, the occupation and Palestinian politics
}

\author{
Simon Faulkner
}

\section{Introduction}

This chapter considers the value Palestinians ascribe to photography in relation to their resistance to the Israeli occupation. The chapter does not, however, discuss specific photographic images depicting aspects of the occupation. Rather it considers Palestinian representations of photography as a medium used to witness the occupation and of photographers as witnesses. This discussion is informed by Lisa Gitelman's conception of a medium as involving the combination of media technology with socially accepted ideas about what that technology does. In her words, media are "socially realized structures of communication" (Gitelman 2006, p. 7). Photography will be understood to involve the interrelation of photographic technologies that enable the capture and transportation of appearances (Berger \& Mohr 1982, p. 92), with shared beliefs about what photographs are and do. Thought about in these terms, what will be termed the photographic witnessing of the occupation will be approached as both the practical matter of photographers using cameras to produce photographic images of this situation and the mobilization of certain ideas about the veracity of photographic images. The argument will be that, in the context of Palestinian struggle against the occupation, the role and meaning of photography as a veracious medium is defined in terms of a moral and political imperative to bear witness to acts of Israeli state violence. The Israeli occupation is a heavily mediated political situation. Part of this mediation involves the production of large numbers of photographic images for quite different purposes (for the commercial news industry, or for human rights and other kinds of activism). Rather than focus on these differences, the concern will be to consider the way that photographs of the occupation have been given meaning in terms of a generic conception of photographic witnessing that is part of Palestinian political culture. This means that a photographer can take pictures of the events of the occupation for largely commercial reasons and still be able to gain a kind of kudos and status in relation to the idea that photographing this subject is a moral and politically meaningful endeavour.

In the first part of the chapter, the interrelated subjects of photographic witnessing, the occupation, and Palestinian politics will be considered in general 

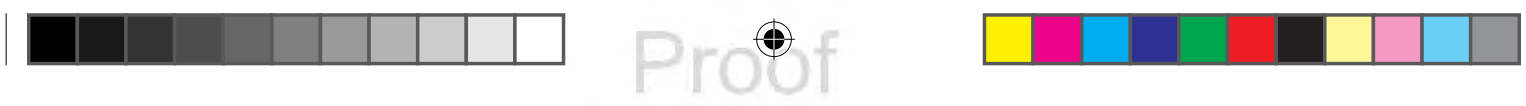

terms, starting with the example of a demonstration in 2006 in the Palestinian village of Bil'in that involved the use of props that represented photographers as an important element of contemporary Palestinian struggle. The second part of the chapter focuses on the self-images of Palestinian photojournalists working in the West Bank, as evidenced through images of themselves that they upload to their Facebook accounts. This movement from a general discussion, organized around the example of the Bil'in demonstration, to a discussion of images of Palestinian journalists is intended to provide different indications of how photographic practices and political virtue have become entwined within the culture of Palestinian resistance. This discussion is also aimed at suggesting a way of exploring photographic witnessing in the context of the Israeli occupation that is not about the political efficacy of that witnessing, but more about what witnessing means in a cultural sense.

\section{Photographic witnessing and the Israeli occupation}

On 9 June 2006, activists in the Palestinian village of Bil'in, which is near Ramallah in the occupied West Bank, created a hand-drawn banner that included a depiction of a camera for one of their weekly demonstrations against the construction of a section of the West Bank Barrier on village land. A photograph (Figure 7.1) by the Israeli activist photographer Oren Ziv shows the making of this banner on the day of the demonstration.

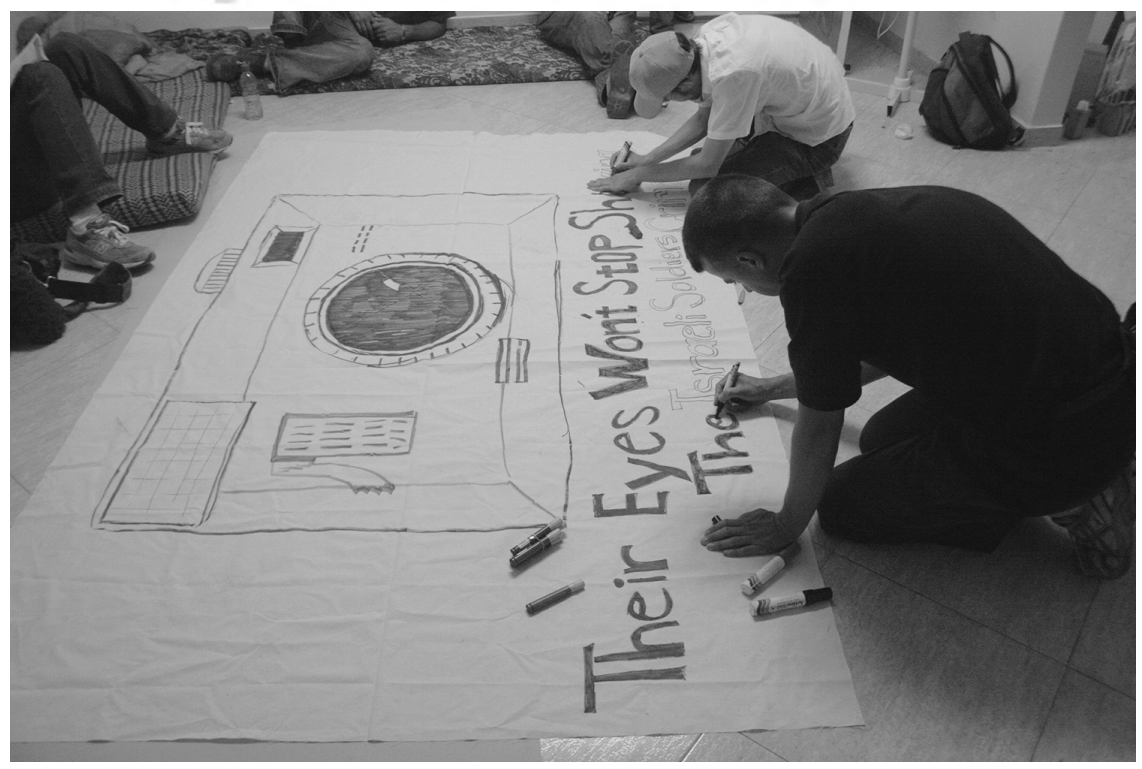

Figure 7.I Oren Ziv/Activestills, photograph of demonstrators creating a banner, Bil'in, West Bank, 9 June 2006.

Source: (C) Oren Ziv. 
The camera on the banner is highly enlarged and rendered as an isolated object on a white background. Below it is the slogan, in English: "Their eyes won't stop showing the Israeli soldiers crimes". The banner represents a high degree of faith in photographic witnessing as a practice. The slogan expresses a sense of certainty that the violent acts of the Israeli military are crimes, but equally it expresses a certainty that the camera has the capacity to show these crimes. The banner is also testament to what the village activists perceived to be the invaluable role in their struggle played by the photographers who have documented their demonstrations (Maimon \& Grinbaum 2016, p. 120). This is something further affirmed by the trophies, constructed by village activists from spent Israeli teargas canisters and grenades, that were awarded to certain photographers and video-activists in 2015, on the tenth anniversary of the beginning of the struggle in Bil'in. ${ }^{2}$

This belief in the value of photographic mediation, as a means of testifying to the reality of the occupation, is longer-standing and appears to have been particularly strong during the first Palestinian Intifada ("shaking off") in the late 1980 s and early 1990s. Although the Intifada was primarily organized in terms of non-cooperation with Israeli governance in the occupied territories, Palestinians were also highly aware of the international mediation of their uprising. This is shown, for example, in the North American writer Norman Finkelstein's account of time spent in the West Bank during the Intifada, in which he recounts visiting the village of Beit Sahour, near Bethlehem, with a photographer friend to see a confrontation between stone-throwing local youth and the Israeli army:

The Beit Sahour villagers in the side street abutting the makeshift stone barricade motioned us inside their homes. They wanted my photographer friend, especially, to have the best possible view of the action. Media consciousness was very high in the occupied territories. The success of the Intifada, everyone seemed convinced, would hinge crucially on world opinion. With whomever I talked, the first question was invariably what the people in the United States were thinking about the uprising. The apparent belief was that, if the truth were known, outside pressure would be brought to bear on Israel.

(Finkelstein 1996, p. 4)

Finkelstein's account suggests that Palestinian resistance in this instance was strongly about being seen. Although political conditions have changed, as have the strategies and technologies used to gain the world's attention to the Palestinian situation, this perceived need to be seen by international audiences has in fact been relatively consistent within Palestinian political culture since the late 1960s. The Palestinian film-maker Azza El-Hassan has suggested that the belief amongst Palestinians that showing the occupation to "the world" will effect political change amounts to a "national illusion" (El-Hassan 2002; Hochberg 2015 , p. 116). Nevertheless, this "illusion" has driven and given meaning to a 
good deal of Palestinian struggle. As Amahl A. Bishara has noted in relation to more recent demonstrations against the occupation, Palestinian activists "perform for audiences they do not know well and will likely never meet" (Bishara 2013, p. 169). This understanding that Palestinians perform political actions that they hope will be mediated to distant spectators, can be applied to the kind of confrontation discussed by Finkelstein, but it applies equally to more conventional forms of demonstration and to instances where Palestinians display the violence of the occupation inflicted on their own bodies to the camera (Collins 2004, p. 67). During the first Intifada, the photographers producing images of the occupation and resistance to it were largely international and Israeli. Since the beginning of the second Intifada in late 2000, a number of Palestinian photojournalists reporting the occupation have also established themselves. This emergence of Palestinian photojournalism, combined with the use of digital cameras and other digital technologies, has meant that the desire to be witnessed is now entwined with an ability on the part of Palestinians themselves to engage in different kinds of photographic witnessing.

The value of photographic witnessing in relation to the occupation, has been addressed in academic texts over the last decade. Although she does not use the term "witnessing", Ariella Azoulay has argued in her well-known book, The Civil Contract of Photography (Azoulay 2008a), that the viewing by Israelis of photographic images of Palestinian suffering can generate alternative civil relations between the photographed person and the spectator that can work against the structural distinction between Israeli citizens and Palestinian non-citizens. In contrast to this, in her book Visual Occupations, Gil Hochberg has responded to the surfeit of documentary and photojournalistic images of the violent effects of the occupation, by observing that photographic eye-witnessing appears to have done little for Palestinians in concrete political terms. These two accounts of the photographic witnessing of the occupation are consequently quite different in character. One involves the philosophical imagining of a civil role for photography, while the other challenges the primacy of visual witnessing as a form of counter-visuality, on the basis that it appears to have little practical effect (Hochberg 2015, p. 31). Azoulay is surely correct when she suggests that Palestinians who show their injuries to the camera lens imagine that the resulting images might be seen by sympathetic spectators (Azoulay 2008a, p. 18). However, her theoretical approach does not examine the concrete relations between the actions taken by people in front of the camera, resultant images, and spectators. Nor does she consider the gaps between the expectations of photographed persons and the actual effects resulting from photographic witnessing. Hochberg, on the other hand, suggests that photographic witnessing might do more harm than good, meaning that "the problem regarding the visibility of Palestinian suffering is no longer that we are unable to see it $[\ldots]$ but rather that it has become almost the only thing we see" (Hochberg 2015, pp. 119-120). From this perspective, visual testimonies of Israeli violence and Palestinian suffering seem to have produced a stereotypical victimhood that occludes Palestinian political agency. 
What both Azoulay and Hochberg do not address in a substantive way is the role of photographic witnessing within Palestinian political culture. Azoulay emphasizes the role of Palestinians as agents who present themselves to be photographed, while Hochberg notes that Palestinians are often amongst those who currently produce photographic testimonies about the occupation (Hochberg 2015 , pp. 31, 116). But neither take these considerations further to think about what political needs are fulfilled and meanings created for Palestinians when they partake in witnessing, either as the witnessed person or as those wielding cameras. It is probably the case that the contemporary emphasis on the witnessing potential of the photographic image is partly the consequence of a crisis of Palestinian politics brought about by the overall failure of the first Intifada and the political compromises of the Oslo process during the 1990s (Allen 2009, 2013; Hochberg 2015, p. 115). Lori Allen in particular has argued that this political crisis has enhanced the ascendancy of forms of visual testimony, which came to stand-in for more substantive forms of political organization and action (Allen 2009). Yet this association of photographic witnessing with political failure affirms, rather than undermines, the argument that such visual practices have become increasingly significant to Palestinian politics. It seems important, therefore, not only to be able to criticize witnessing practices as a relatively weak and perhaps counter-productive form of political practice, but also to find ways to gain a richer understanding of how Palestinians have enacted witnessing as a form of resistance under challenging political conditions and through this, explore how such practices have enabled the cultivation of particular political identities.

This last point leads us back to the drawing of the camera on the banner in Bil'in, which was combined, not only with the English language slogan, but also with a drawing of a disembodied arm and hand making a victory sign of the kind ubiquitous within images relating to Palestinian resistance, and an image of another arm that appears to be holding some sort of weapon, or perhaps a pen to denote written journalism. Consequently, the camera is linked to at least one explicit symbol of Palestinian resistance and as such is framed as a figure of Palestinian political struggle. Another photograph by Oren $\mathrm{Ziv}$ shows the banner in use during the demonstration (Figure 7.2).

A mock pentagonal martyr's memorial, constructed from white cardboard, is also shown being carried behind the banner. On its sides were written in English and Arabic the names of five journalists and photojournalists killed during the second Intifada. Images of these dead media workers were also attached to the top of the memorial. The text visible on the front side of the memorial states, "The Martyr: James, British, killed in Rafah", referring to the British documentary cameraman James Miller, who was killed by Israeli forces in Gaza in May 2003, while making the film Death in Gaza (2004). ${ }^{3}$ The conjunction of the banner and the memorial in Ziv's photograph, suggests that this particular demonstration was themed around the figures of the journalist and the photojournalist. This combination of the banner and the memorial brings together two 

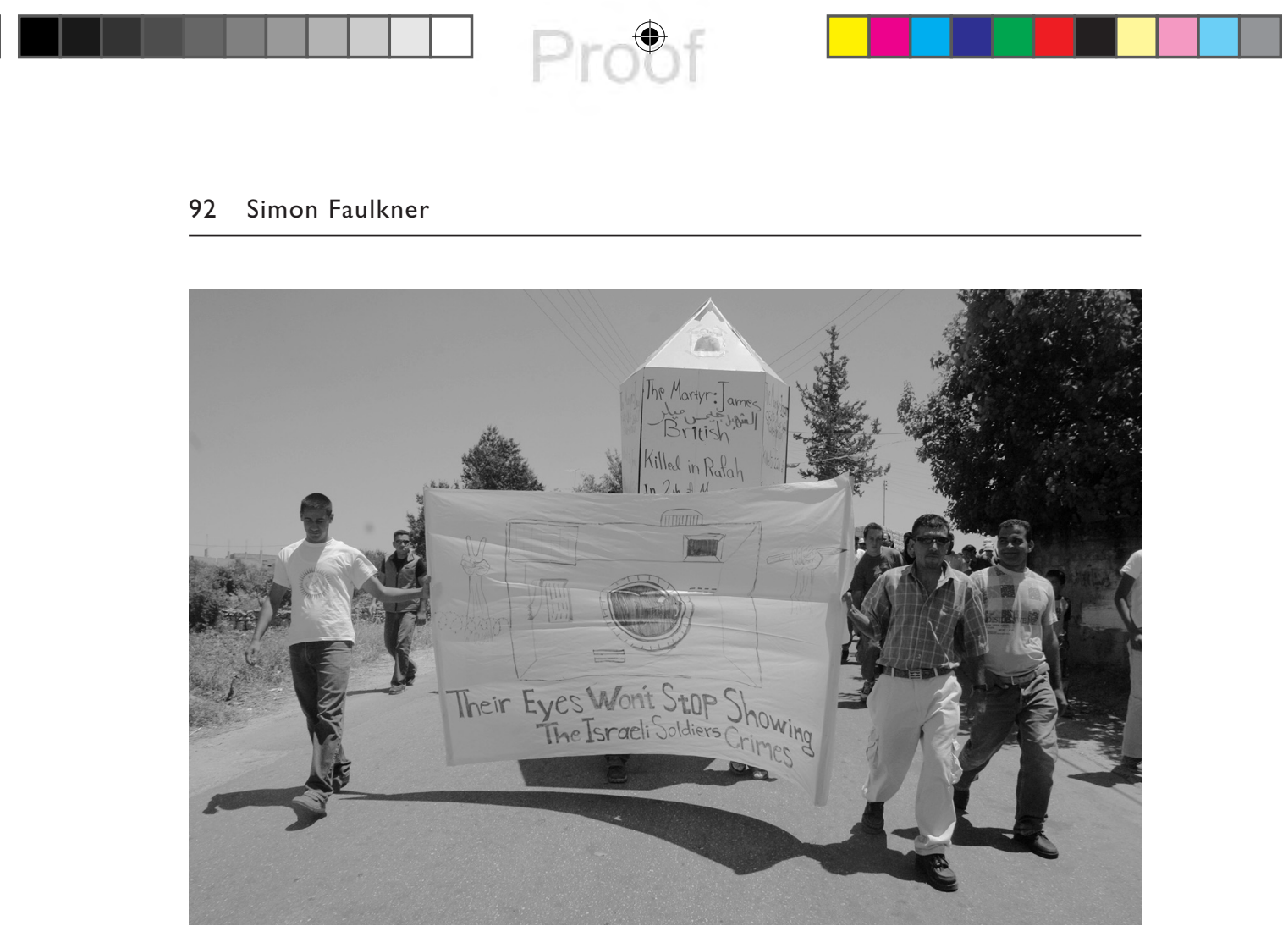

Figure 7.2 Oren Ziv/Activestills, photograph of demonstrators carrying a banner and mock martyrs' memorial, Bil'in, West Bank, 9 June 2006.

Source: () Oren Ziv.

key concepts fundamental to the cultural construction of the photojournalist in the Palestinian context. The first concept being the idea, already discussed, that photography is a medium that can straightforwardly show the violence of the occupation, while the second is the understanding that photographers take risks and face dangers, up to and including death, to engage in the practice of photographic witnessing. Defined in these terms, photojournalists, especially when Palestinian, are not perceived to be third-party observers who represent the occupation from a position of disinterestedness. On the contrary, photojournalists, by virtue of their struggle for the truth, are understood to be thoroughly implicated with wider political resistance to Israeli domination (Bishara 2013, p. 158). The slogan on the banner, "Their eyes won't stop showing the Israeli soldiers crimes", itself suggests commitment to a cause that is unending in a way comparable to broader conceptions of the unwavering and steadfast nature of Palestinian resistance. What this means is that the "gruelling" labour of photojournalistic work in the occupied territories (Bishara 2013, p. 2) is invested with moral and political import that goes well beyond its professional and newsrelated meanings. This construction of the photojournalist, as someone who struggles and takes risks to bear witness, fits with the international understanding of witnessing, described by Michal Givoni as the "heroic notion of witnessing", 
otherwise bound to be concealed, denied, or forgotten, so as to infuse the cause of its victims with the power of facts" (Givoni 2016, p. 6). Yet this generic construction of witnessing is inflected in the Palestinian context by specific concerns arising from the conditions of life and resistance under occupation. This means that the photojournalist killed while at work is not simply an unfortunate victim of the risks of this profession, but a martyr for the cause (Bishara 2013, p. 158).

\section{Palestinian photojournalists, witnessing and Facebook}

In her discussion of the witness as an actively produced moral and political subject, Givoni notes that witnesses are people who are meant to perform the "arduous trial" of becoming a witness and at the same time putting this performance "on display" (Givoni 2016, p. 12). A specific example of this relationship between witnessing and the self-presentation of this role can be found in the way that Palestinian photojournalists have used images of themselves, engaged in their photographic work, as iconic markers of the political aspects of their identities as photographic witnesses. The rest of this chapter will focus on the use of such images on the professional and personal Facebook pages of a number of Palestinian photojournalists as a way of continuing the discussion of the political significance of photographic witnessing in the context of the occupation. These images often focus on the challenges and dangers specific to working as a Palestinian photojournalist within the occupied territories. The photojournalists often travel and work together, especially when photographing confrontations between Palestinians and the Israeli military, as being in a group enables a higher degree of visibility and protection from the Israeli army who, in theory, are not meant to target journalists (Bishara 2013, pp. 93-96, 243). This situation also provides opportunities for photojournalists to become the subjects of images taken by other photographers. Such images can be distributed in the same way as other news images, but they also become part of a more socially-oriented visual economy in which images are shared within photojournalistic peer-networks. This exchange of images of each other between Palestinian photojournalists precedes the development and popularization of digital cameras and social media (Bishara, 2013, p. 145). However, the adoption of digital technologies seems to have intensified this practice, especially because social media platforms provide Palestinian photographers with readymade opportunities to display these images of their struggles to bear witness.

Before addressing the use of these images on Facebook, it is useful to discuss further the emergence of Palestinian photojournalism. There exists a wellestablished photojournalistic infrastructure of picture agencies and wires, centred on Jerusalem, that employs international, Israeli and Palestinian photographers who document both the exceptional and regular events of the occupation. Over the last decade, such events have included weekly demonstrations against settlement expansion and the West Bank Barrier in multiple locations on the West 
Bank, mostly within specific villages such as Bil'in. These demonstrations have constituted a relatively small-scale and fragmented resurgence of unarmed "popular struggle" after the second Intifada (Darweish \& Rigby 2015). The closure of the occupied territories during the second Intifada produced a greater need on the part of international news organizations for locally-based Palestinian photographers, who could cover events in areas inaccessible to international or Israeli photojournalists (Bishara 2013, p. 176). Many of the more senior and established Palestinian photojournalists currently working as staff at agencies and wires began work during this period. Younger photographers, who followed their lead, generally work as "stringers" or freelancers for the same international organizations, although they also work for local Israeli and Palestinian picture agencies, such as Flash 90 and APA Images. In more recent years, a number of Palestinian photographers have also emerged who document demonstrations in the West Bank with the aim of circulating their images on social media (Bizawe 2014; Brown 2014).

The situation of Palestinian photojournalists differs from international and Israeli photographers working in the West Bank, insofar as they are much more likely to be arrested, hurt and even killed by the Israeli army while photographing demonstrations against the occupation (Bishara 2013, pp. 93-96). Palestinian journalists in general can also have a different relationship to dominant international notions of journalistic "disinterestedness" that, in Bishara's words, are meant to "separate between the politics journalists cover and the lives they live" (Bishara 2013, p. 109). Living and working under the occupation can make it difficult for Palestinian journalists to separate their professional activity from the conditions of their everyday lives and from the wider political struggles arising from the occupation. This does not necessarily cause a contradiction between "objective" reporting and their sense of responsibility to report the injustices of the occupation. Indeed, as already discussed, wider Palestinian ideas about photographic witnessing strongly link the assumed capacity of photography for veracity or objectivity to the role it is imagined to have within the national struggle. Nonetheless, these photographers can be pulled between the competing commitments of professional journalism and membership of a highly politicized community (Bishara 2013, p. 124). This pull between the dominant professional discourses of international photojournalism and Palestinian national politics is of particular interest when it comes to Palestinian photographers using social media, where the platforms, unlike news production companies, allow for the expression of political commitments.

Palestinian photographers express such political commitments on Facebook through the use of "Profile Pictures" and "Cover Photos" as well as through the posting of images, texts, and links on the platform "Timeline". The discussion presented here will focus on the use of images of photojournalists engaging in their photographic work as Facebook Cover Photos. Such images are interesting because they are often visible for much longer than images posted on the Timeline and also because account holders use these images to frame their platform-based 
identities. The photographers to be discussed here occupy different positions in relation to the photojournalism industry. Some are staff at news organizations, while others are freelancers, activists, or both. Yet their use of photographs of themselves involved in confrontations with Israeli soldiers, or experiencing other aspects of the violence of the occupation regime as Cover Photos is similar. This suggests that many Palestinian photojournalists experience similar conditions of harassment and violence when working. Yet, it also suggests that such images have a similar value for all of these photographers, despite their differing degrees of professionalization. Many of these images depict an oppositional relationship between the photographer and Israeli soldiers. This kind of oppositional scene has been recurrent within the visual representation of the occupation since at least the 1980s, if not before (Azoulay 2008b). In this sense, the victimization of photojournalists, as represented in the images under discussion, replays imagery that is already strongly embedded within the photographic archive relating to the occupation. This is particularly the case with images of photojournalists being arrested, which resonate with a longer history of the depiction of Israeli soldiers arresting Palestinians, especially during the first Intifada. For example, a Cover Photo used by the freelance photographer Shadi Hatem in 2016, shows him being held in a headlock by an Israeli soldier as he is being detained. Earlier Cover Photos show him being intercepted by soldiers or carried forcibly into an Israeli army jeep. This is also the case with the older Nablus-based Reuters stringer Abed Omar Qusini, who used a Cover Photo showing him being detained by a soldier while another photographer takes a picture of this event. A different kind of image, with a similar theme, has also functioned as the Cover Photo for the Reuters' staff photographer Ammar Awad for nearly five years.

Figure 7.3 shows a group of Palestinian children taking part in a demonstration against restrictions on press freedom in Ramallah, for which the Palestinian Authority printed large images of Palestinian journalists and photojournalists being arrested by the Israeli army. In the image, two girls are holding a large print of a photograph of Awad being arrested by three Israeli soldiers at a demonstration in Bil' in in 2007.

Another recurrent motif involves photojournalists arguing with soldiers, presumably after the soldiers have tried to stop them photographing, or when the soldiers are in the process of arresting the photographers. This motif has been used by Shadi Hatem and by the young Ramallah-based freelancer Ahmad Talat Hassan (Figure 7.4).

The argument motif is also repeatedly present amongst the Cover Photos used by the Bil'in-based activist photographer Hamdi Abu Rahma. In contrast to the images of photojournalists actually being arrested, which frame Palestinian photographers as subject to Israeli military power, these images of Abu Rahma remonstrating with Israeli soldiers present him as an antagonist within a political struggle. The photographer is shown speaking back to the "petty sovereigns" (Butler 2004, p. 56) of the occupation. Abu Rahma's Cover Photos present him as an active participant in a political and somewhat militarized contest, within 

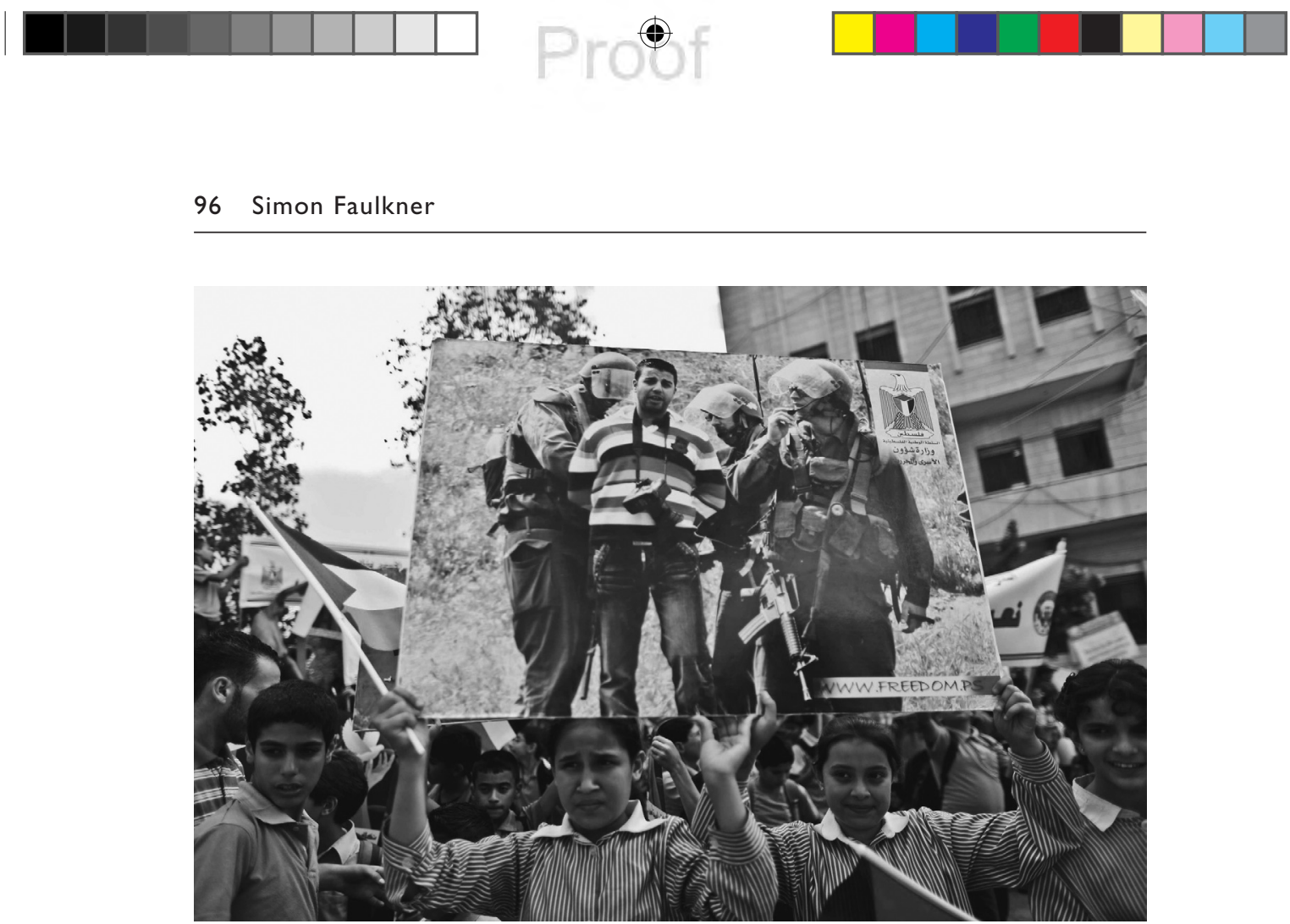

Figure 7.3 Amar Awad, photograph of Palestinian children taking part in a demonstration against restrictions on press freedom in Ramallah in the West Bank in 2012. The children carry a large photograph of Israeli soldiers detaining the photojournalist Amar Awad at a demonstration in Bil'in in 2007. Used as a Facebook banner by Amar Awad.

Source: () Amar Awad.

which the camera is understood as a kind of weapon. This is made more explicit by another Cover Photo that shows him and two other Palestinian photographers arguing with four Israel soldiers. A text written by Abu Rahma to accompany and describe this image, reads: "camera, gun, camera, gun, gun, camera, gun ... and who will win?" This setting up of the camera against the gun as a different kind of weapon is made even more explicit through Abu Rahma's use of a graphic image as a Cover Photo that depicts a soldier pointing a rifle at a photographer who points a camera back at him.

Other recurrent images used as Cover Photos are those that depict Palestinian photojournalists experiencing adverse conditions arising from the events they photograph, or purposely inflicted upon them by Israeli forces. The photojournalist affected by or within teargas is a particularly striking motif, used, for example, by Ashraf Amra, a freelancer who works for APA Images, and also by the Associated Press stringer Madji Mohammed. Hamdi Abu Rahma also used a more performative image of himself wearing a gasmask with teargas around him, while Abed Omar Qusini used a photograph of himself about to be engulfed by a cloud of gas. Similar to such images of photojournalists facing hardships 

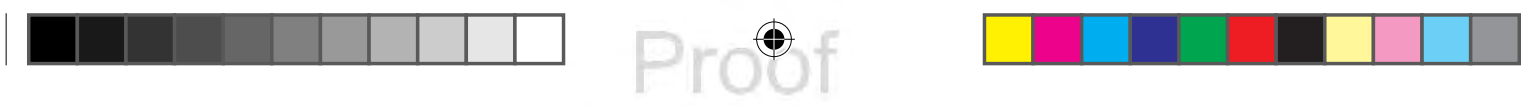

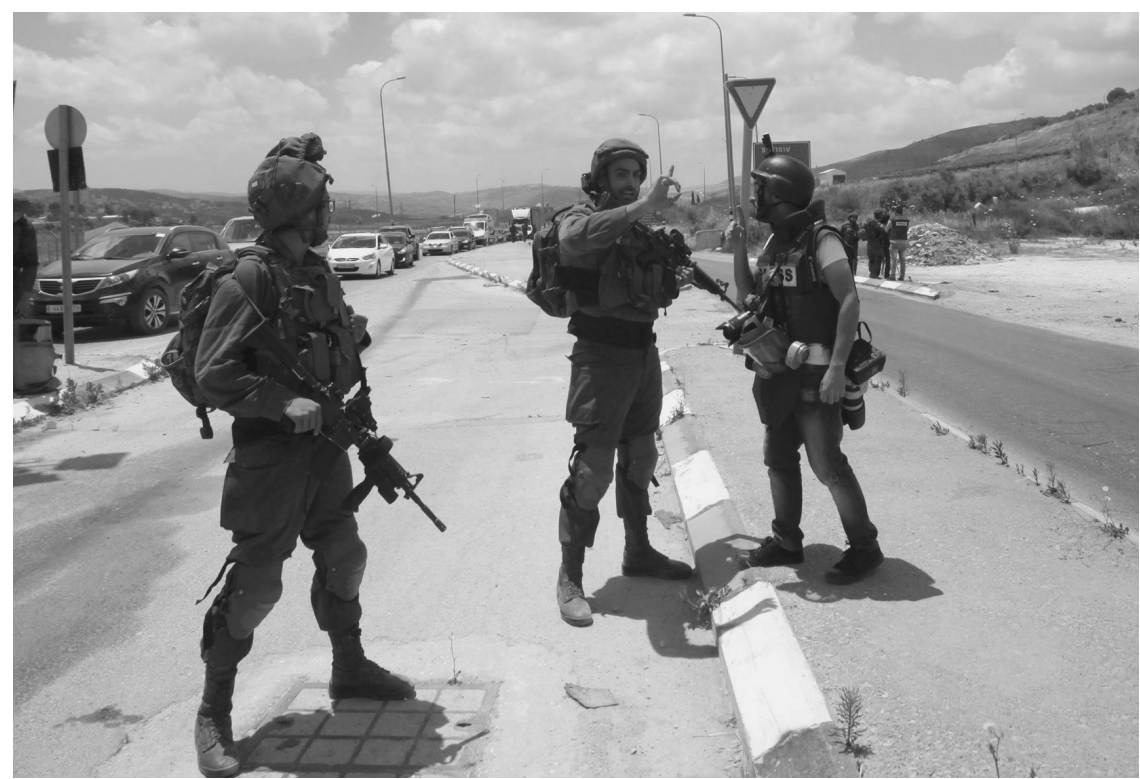

res

Figure 7.4 Nidal Eshtayeh, photograph of photojournalist Ahmad Talat Hasan arguing with Israeli soldiers, location unknown, 2017.

Source: (c) Nidal Eshtayeh.

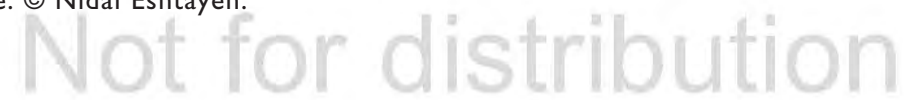

while they work, are images of injured photographers. For example, the Anadolu Agency staff photographer Issam Rimawi has used an image of himself holding up his injured arm, perhaps hit by a gas canister, to be inspected by the Agence France-Presse photographer Abbas Momani. Like the images of photojournalists being arrested, these images separate photographers out as a particular kind of agent, while also representing them as being in a similar position to any Palestinian exposed to Israeli military violence within protest situations.

What should be made of the use of these different photographic images as Facebook Cover Photos? Are we to take them as simply illustrative of the experiences of particular photographers, or do they have a more generic significance relating to the role of Palestinian photographers as politically interested witnesses to struggles between Palestinian communities and the Israeli military? One point of reference when considering these questions is the international tendency to represent photojournalists in a romantic light, as adventurers and risk-takers in search of striking news images. As Beth E. Wilson has recently shown, the romanticized figure of the photojournalist was largely a corporate creation produced by organizations such as Life magazine during and after the Second World War (Wilson 2016). There is something of this romantic construction of the photojournalist in the Cover Photos used by the Palestinian 
photographers under discussion here. Yet, with reference back to the earlier discussion of the political value of photographic witnessing in the occupied territories, the romanticism involved in these specific images also invokes a history of generally masculinized resistance to colonization and occupation that is particular to the Palestinian situation. One might think of other figures who have constituted the iconography of Palestinian national resistance: the guerrilla fighter, or fedeyeen ("one who risks his life voluntarily"), or the figure of the child throwing stones at Israeli soldiers (Khalili 2007; Kimmerling \& Migdal 2003, p. 243). The risk-taking, arrested, gassed, or injured Palestinian photojournalist, as represented in the Cover Photos discussed so far, is not the same as these other figures, but nonetheless, carries something of their meaning. Thus, in response to Ashraf Amra's use of the image of him suffering from exposure to teargas, one respondent described him as a "fighter", while in response to one of Shadi Hatem's Cover Photos, another respondent calls him a "warrior". Through these terms, photographing the occupation is equated to other forms of resistance to the Israeli military. As already pointed out in relation to the banner and mock memorial used in the demonstration in Bil'in, photojournalism is reframed as something that is not just reportage, or professional work, but also a form of struggle. This is most clear in the selfpresentation of social-media oriented activist photographers such as Hamdi Abu Rahma, but it is also implied through the use of particular Cover Photos by other photographers. As Bishara observes: "Palestinian photojournalists who put themselves in the line of fire, or in the cloud of tear gas, are assuming embodied political stances that have undeniable moral significance in Palestinian society" (Bishara 2013, p. 158). The Cover Photos under discussion depict these "embodied political stances", transforming them into iconic scenarios that locate photojournalistic identity in terms of a struggle to witness the truth under adverse conditions. These adverse conditions are part of the occupation, meaning that the very struggle to bear witness has a value as resistance in and for itself. This struggle is not merely thought about as work, even by those photographers most involved with the commercial production of news images, but also as a heavy responsibility, or in Ahmad Talat Hasan's words as a "sacred mission". He uses this phrase in a post on his Facebook Timeline that reports on him being wounded in the leg while photographing a demonstration in the village of Kafr Qaddum near Nablus in 2015. This post was illustrated by three images: one a photograph of the injured Hasan being carried from the demonstration, one a photograph of his bandaged leg, and the third an X-ray of the leg. These different documents of his wounding affirm the implied relationship between the "mission" of the photojournalist and self-sacrifice, at least in terms of pain and hardship. In these terms, these images and the Cover Photos already discussed constitute a genre of imagery that frames the work of photographers within their own subcultural social-media context and for other Pales- 


\section{Conclusion}

The aim of this chapter has been to suggest that there is a need to address the use of photographic witnessing as part of Palestinian political culture, and to explore the value and meanings ascribed to these practices aside from their practical impact. The chapter has dealt with this subject in terms of examples of the cultural construction of the photographer as someone who takes risks and makes sacrifices (including martyrdom) to witness the truth of the occupation. The framing of the photographer as someone who is a potential and sometimes actual martyr entails a particular manifestation of the etymological relationship between the martyr and the witness, the person who sacrifices their life being the ultimate witness (Schankweiler \& Straub 2016). The discussion has also considered the reiteration of this cultural construction of the photographer by Palestinian photographers themselves, through their use of images of themselves being arrested or facing adverse conditions while undertaking photographic work. This use of such images as Cover Photos on Facebook involves an investment in self-images congruent with long established romantic representations of the photojournalist that are also inflected with meanings relating to Palestinian nationalism that makes the mythic heroism of the photographer analogous to other masculine figures of Palestinian struggle.

Palestinian photojournalists think of photographs as visual documents that can make the violence of the occupation visible to others, yet, their commitment to the imagined political power of photography is not dependent on any certainty about its political effects. Rather, this commitment to the perceived veracity of photography is largely a matter of a socially embedded "faith" in the value of photographic witnessing (El-Hassan 2002) and should be approached as such. As Hochberg has argued, there are clearly problems in political terms with having too much faith in the power of images to alleviate and change abject political conditions, but still, it is important to understand how such a faith has arisen and how it works. With this in mind, the chapter has suggested a more cultural approach to thinking about photographic witnessing in relation to Palestinian political struggle. This specific context also suggests the need to adapt critical distinctions between professional photographic and citizen-witnessing. This is not only necessary because the situation of Palestinians living under occupation in the West Bank is one that denies them formal citizenship, meaning that their position as "citizens" is an aspirational rather than formal one, but also because the practices of the Palestinian photographers discussed often involve complex and sometimes contradictory relationships between their professional roles within photojournalism and their situation as people living under occupation. Under such conditions, social media appears to have offered such photographers virtual contexts within which to present themselves in more political terms, allowing differing degrees of intersection between their professional practices and their embeddedness in a politically saturated situation. 


\section{Notes}

1 Photographs of the banner were found in the Activestills online archive, which is part of their website: http://activestills.org/archive.php [26 February 2018].

2 One of these trophies was shown to me in 2015 by the Israeli artist and video-activist David Reeb.

3 The other four journalists and photojournalist recorded on this mock memorial were: the Palestinian cameraman Nazih Datwazeh, killed in Nablus in April 2003; the Palestinian journalist Issam Hamza Al Tilawi, killed in Ramallah in September 2002; the Palestinian journalist Imad Abu Zahra, killed in Jenin in July 2002; the Italian photojournalist Raffaele Ciriello, killed in Ramallah in March 2002. For further information about this aspect of the demonstration on 9 June 2006, see Jacob Katriel's blog: http:// jacob-katriel.tripod.com/id15.html [6 February 2018].

\section{References}

Allen, L. (2009). Martyr bodies in the media: Human rights, aesthetics, and the politics of immediation in the Palestinian Intifada. American Ethnologist, 36(1), pp. 161-180.

Allen, L. (2013). The Rise and Fall of Human Rights: Cynicism and Politics in Occupied Palestine. Stanford, CA: Stanford University Press.

Azoulay, A. (2008a). The Civil Contract of Photography. New York: Zone Books.

Azoulay, A. (2008b). Act of State: 1967-2007: Photographed History of the Occupation. Tel Aviv: Etgar (Hebrew).

Berger, J. \& Mohr, J. (1982). Another Way of Telling. London: Writers and Readers Publishing.

Bishara, A.A. (2013). Back Stories: U. S. News Production and Palestinian Politics. Stanford, CA: Stanford University Press.

Bizawe, E.S. (2014) Gaza war images you won't see on Israeli TV. Haaretz. Available from: www.haaretz.com/israel-news/culture/leisure/.premium-1.608931 [11 May 2018].

Brown, L. (2014). Photojournalism in the Palestinian territories. Open Democracy. Available from: www.opendemocracy.net/north-africa-west-asia/liam-brown/photojournalismin-palestinian-territories [11 May 2018].

Butler, J. (2004) Precarious Life: The Powers of Mourning and Violence. London and New York: Verso.

Collins, J. (2004). Occupied by Memory: The Intifada Generation and the Palestinian State of Emergency. New York: New York University Press.

Darweish, M. \& Rigby, A. (2015). Popular Protest in Palestine: The Uncertain Future of Unarmed Resistance. London: Pluto Press.

El-Hassan, A. (2002). Art and war. Ars Electronica. Available from: http://90.146.8.18/ en/archives/festival_archive/festival_catalogs/festival_artikel.asp?iProjectID=11789 [10 May 2018].

Finkelstein, N.G. (1996). The Rise and Fall of Palestine: A Personal Account of the Intifada Years. Minneapolis and London: University of Minnesota Press.

Gitelman, L. (2006). Always Already New: Media, History, and the Data of Culture. Cambridge, MA and London: The MIT Press.

Givoni, M. (2016). The Care of the Witness: A Contemporary History of Testimony in Crises. New York: Cambridge University Press.

Hochberg, G.Z. (2015). Visual Occupations: Violence and Visibility in a Conflict Zone. Durham and London: Duke University Press. 
Khalili, L. (2007). Heroes and Martyrs of Palestine: The Politics of National Commemoration. Cambridge, UK: Cambridge University Press.

Kimmerling, B. \& Migdal, J.S. (2003). The Palestinian People: A History. Cambridge, MA and London: Harvard University Press.

Maimon, V. \& Grinbaum, S. (eds) (2016). Activestills: Photography as Protest in Palestine/Israel. London: Pluto Press.

Schankweiler, K. \& Straub, V. (2016). Shaheed. Aesthetics of Resistance, Pictorial Glossary, The Nomos of Images. Available from: https://nomoi.hypotheses.org/824 [10 May 2018].

Wilson, B.E. (2016). The corporate creation of the photojournalist: Life magazine and Margaret Bourke-White in World War II. Journal of War and Culture Studies, 9(2), pp. $133-150$. 